\title{
Fractal Geometry Based Chakra-shaped Microstrip Patch Antenna Array for Vehicular Communications Under 5G Environments
}

ABDUL RAHIM ( $\nabla$ rahim.mrecw@gmail.com )

Lovely Professional University https://orcid.org/0000-0003-0086-4733

Praveen Kumar Malik

Lovely Professional University

\section{Sudipta Das}

IMPS College of Engineering and Technology

\section{Research Article}

Keywords: Microstrip patch antenna, fractal geometry, 5G, multi-patch array, vehicular communications

Posted Date: February 24th, 2022

DOl: https://doi.org/10.21203/rs.3.rs-1348946/v1

License: (c) (i) This work is licensed under a Creative Commons Attribution 4.0 International License.

Read Full License 


\title{
Fractal Geometry based Chakra-shaped Microstrip Patch Antenna array for Vehicular
} Communications under $5 \mathrm{G}$ Environments

Abdul Rahim ${ }^{1}$, Dr. Praveen Kumar Malik ${ }^{2}$, Dr.Sudipta Das ${ }^{3}$

${ }^{1-2}$ School of Electronics and Electrical Engineering,Lovely Professional University, Punjab, India, ${ }^{3}$ Department of Electronics and Communication Engineering,IMPS College of Engineering and Technology,Malda,West Bengal,India rahim.mrecw@gmail.com,pkmalikmeerut@gmail.com,sudipta.das1985@gmail.com

\begin{abstract}
In this paper, fractal geometry based two printed antenna structures are proposed for vehicular communication in $5 \mathrm{G}$ wireless communication networks. Initially, a $48 \times 39 \mathrm{~mm}^{2}$ single element fractal patch antenna is designed and tested which shows dual band resonance at around $28.1 \mathrm{GHz}$ and $32.5 \mathrm{GHz}$. In order to improve different antenna characteristic descriptors such as bandwidth, reflection coefficient, voltage standing wave ratio (VSWR), and gain, number of fractal radiating elements have been increased to four and constructed an array of patches such that it can be used for multiple applications in the field of vehicular communications. For better performance, the antenna is replicated in the form of a $2 \times 2$ patch array such that the performance can be increased by at least $20 \%$. The proposed array model is fabricated on a Rogers RT duroid 5880tm material of size $115 \times 82 \mathrm{~mm}^{2}$ and tested using Agilent Technologies N5247A VNA. The measured results confirm the validity of the designed model for intended applications. The proposed array antenna operates at distinct quintuple bands in the frequency range of $25-36 \mathrm{GHz}$ for vehicular communication within the proposed lower fifth generation $(5 \mathrm{G})$ channel. The proposed array configuration shows a good peak gain of $6.72 \mathrm{~dB}$ within the operating bands.
\end{abstract}

Keywords: Microstrip patch antenna, fractal geometry, 5G, multi-patch array, vehicular communications.

\section{Introduction:}

Traditionally from 1 st generation to 4 th generation, there was an impact on the hardware advancements only, but as per the latest technology of 5G, there is a direct impact on software [1]. With the advancements of software, the level of computational capacity has increased which provides a scope of automobile communication. This provides the technology to be self-configure, self-healing and self-analysis. Location information can be accessed very easily as the technology has very good self-informative system available in itself [2]. This all is achieved as the technology has a direct impact on software accessing and development. Using cooperative localization, deviceto-device communication is enabled to its highest position where multiple applications are entitled to it [3]. Internet of things (IoT) is another field in which the impact is directly observed as the sensors are intact with the $5 \mathrm{G}$ communication, where the latency can be reduced and the active time of the device can be improved. The range of communication can be increased with the milli-meter technology incorporated using 5G [4].Health and medical sciences areanother areas where the impact of $5 \mathrm{G}$ is directly seen as the high frequency can be used to scan the organs and give a better understanding of the health of the patient [5].Vehicular communication is another area where the impact is seen as a vehicle to everything is largely exposed to the technology which includes communication using Vehicle to Vehicle(V-V), vehicle to infrastructure (V-I), vehicle to pedestrian (V-P), and vehicle to the user (v-u) [6]. This has brought the automobile industry to its highest technology-based movable vehicles. The communication unit is set up at different vehicles, roadside units, and other objects which are needed to provide the information. These units are to be 
in contact and should provide the information continuously [7]. The information regarding the roads, the way the curves are ahead, weather information, and other necessary information are stored in the cloud which can be accessed by the vehicle to provide the information to the user [8]. As the information is endless and continuous which is very much needed for the user to understand the vehicle and the road better, there is an emergency need of having a proper end-to-end connection. Wireless communication comes to existence as it provides information via wireless connectivity [9].

In this era, it is very much clear that the technology surrounded with $5 \mathrm{G}$ has an impact on the luxury, safety, security, and comfort of the individual [10]. Society is benefited fromthis technology which makes it as an essential commodity for day to day life. Table 1 provides the information regarding the proposed Spectrum under $5 \mathrm{G}$.

Table 1: Proposed spectrum under 5G for various countries [1]

\begin{tabular}{|l|l|l|l|l|}
\hline Countries & Channel-1 & Channel-2 & Channel-3 & Channel-4 \\
\hline $\begin{array}{l}\text { US Proposed } \\
\text { Spectrum }\end{array}$ & 24.25 to $27.5 \mathrm{GHz}$ & 31.8 to $33.4 \mathrm{GHz}$ & 37 to $40.5 \mathrm{GHz}$ & 40.5 to $42.5 \mathrm{GHz}$ \\
\hline $\begin{array}{l}\text { EUROPE Proposed } \\
\text { Spectrum }\end{array}$ & 27.5 to $29.5 \mathrm{GHz}$ & 37 to $40.5 \mathrm{GHz}$ & 47.2 to $50.2 \mathrm{GHz}$ & 50.4 to $52.6 \mathrm{GHz}$ \\
\hline $\begin{array}{l}\text { SOUTH KOREA } \\
\text { Proposed Spectrum }\end{array}$ & 28.4 to $32.4 \mathrm{GHz}$ & 41.25 to $43.75 \mathrm{GHz}$ & 59.3 to $71 \mathrm{GHz}$ & ----------- \\
\hline $\begin{array}{l}\text { CHINA Proposed } \\
\text { Spectrum }\end{array}$ & 31.75 to $33.54 \mathrm{GHz}$ & 45 to $47 \mathrm{GHz}$ & 59 to $64 \mathrm{GHz}$ & ----------- \\
\hline
\end{tabular}

At these frequencies, there is a very much need for an antenna that should have a good gain, multiband, highly directive with compact in size.

The best antenna for the fulfillment of this is a microstrip patch antenna, which can be used for very high frequencies, but the drawback of the antenna is, it possesses low gain, low bandwidth which will have an impact directly on the performance of the antenna. There are many ways to overcome these drawbacks such as fractal geometry which provides self-similarity and improves the performance of the antenna. The alternate is to design a multi-patch that increases the antenna dimensions yet can be used for multiple applications. The antenna patch can be implemented using fractal designs like Sierpinski carpet, Minkowski island, snowflake [7], these designs are based on fractal geometry which is an endless, self-similar design [11]. Over the years these shapes are used in the design of antennae at frequencies not greater than 10Giga Hertz $(\mathrm{GHz})$.

In this paper fractal geometry based single and multi-patch antenna are presented. The antennas are simulated and measured at futuristic $5 \mathrm{G}$ frequencies for vehicular applications, where the size of the single patch is $39 \mathrm{~mm} \times 48 \mathrm{~mm} \times 0.55 \mathrm{~mm}$ and $2 \times 2$ array antenna is $82 \mathrm{~mm} \times 115 \mathrm{~mm} \times 0.55 \mathrm{~mm}$. The antennas are tested under frequency range of $25 \mathrm{GHz}$ to $35 \mathrm{GHz}$. The advantage of $2 \times 2$ array antenna are its miniaturized dimensions achieved by using fractal geometry, antenna resonates at multiple bands with enhanced operating bandwidths, a maximum gain of $6.72 \mathrm{~dB}$ with Voltage Standing Wave Ratio (vswr) of 0.715 and reflection coefficient of $-27.71 \mathrm{~dB}$ at the frequency of 32.8GHz. The antennas are simulated using High Frequency Structure Simulator (HFSS) v15 and measured using N5247A Vector Network Analyzer (VNA). 


\section{Related Works:}

In this section, the latest research works carried out by various researchers in the domain of vehicular communications, fractal antennas, and 5G communications are presented. The focus is majorly on the parameters of the antenna and the behavior of the antenna at futuristic frequencies. The authors [12] proposed a Hexagonal shaped ultra-wide bandwidth Fractal dipole antenna for frequency range 0.5 to $12 \mathrm{GHz}$. The simulation is carried out to focus on the gain of the antenna which was around $6.9 \mathrm{dBi}$ for various angles of penetration. The proposed fractal module is very tiny in its size and shape which can be used for vehicular communications. A minimum reflection coefficient of $29.19 \mathrm{~dB}$ was achieved and the VSWR was in the range of $4 \mathrm{~dB}$.In the next analysis, the author [13] proposed a triangular-shaped fractal geometry antenna for UWB applications. The self-complementary principle is applied at the first iteration of the planner triangular monopole antenna for its enhancement. Through this principle, it is observed that the reflection coefficient is reduced to below $10 \mathrm{~dB}$ for a frequency range of 4 to $11 \mathrm{GHz}$. The triangle patch is compared with single and multiple patches in which the performance level was enhanced up to $30 \%$. The idea of studying this antenna leads us to design antenna both single and multi-layer patch. One of the key features of the antenna is to design such that it can be used for multiple applications. The author [14] proposed Fractal based Hexagonal wide slot antenna for super wide-band applications. The proposed antenna achieves a ratio impedance bandwidth 15:19 for a frequency range of 3 to $30 \mathrm{GHz}$ for VSWR $\leq 2$.The achieved bandwidth is double when compared with the required bandwidth of SWB operation. For bandwidth enhancement, even at lower frequencies, the author proposed a hexagonal tuning stub loaded at microstrip feed line which is a very good idea for the compact antennas which can be placed on a vehicle.

The latest requirements of the antenna are to make it wearable and conformal which can be placed on the human body for providing the required information. The author [15] proposed a wearable Fractal monopole antenna embedded with a reflector for better antenna performance and SAR reduction. The proposed antenna shows improved bandwidth of $130 \mathrm{MHz}$ in the free space and $128 \mathrm{MHz}$ when mounted on a flat homogeneous phantom at an operating frequency of 2.36 to 2.50GHz.The bandwidth of the antenna is the most important feature for any application and the author [16] had proposed about Fractal antenna with a modified hexagonal shape with multiband notch characteristics for UWB applications. The antenna is fabricated using FR4 Epoxy which leads to obtaining a bandwidth of $2.36 \mathrm{GHz}$ in the frequency range of $9.8 \mathrm{GHz}$ to $15 \mathrm{GHz}$ with $\mathrm{S}_{11}$ is less than $-10 \mathrm{~dB}$ over the entire UWB range. The author mentioned that these improved features provide several applications in the field of telecommunication and vehicular communications. The aboverelated work has provided a lot of understanding regarding the design of the proposed work to make it useful for multiband applications in vehicular communications under $5 \mathrm{G}$ environments. The slots have been introduced in the design to achieve wide-band and to achieve multiband characteristics with wide impedance. The antenna is also designed using a single patch and multi-patch design which is described in the next section. 


\section{Antenna Design}

\subsection{Microstrip Patch Antenna with Single Patch:}

The single element patch antenna is designed using a self-similar pattern with the same dimensions as the rectangular patch of $39 \mathrm{~mm} \times 48 \mathrm{~mm}$. The antenna is designed using the Rogers RT duroid $5880 \mathrm{tm}$, with a relative permittivity of 2.2 . The patch is of circular shape and internally made of seven iterations, with each iteration radius is reduced by $1 \mathrm{~mm}$ as shown in Figure 1.The single element fractal antenna resonates at dual band due to the suggested antenna geometry.

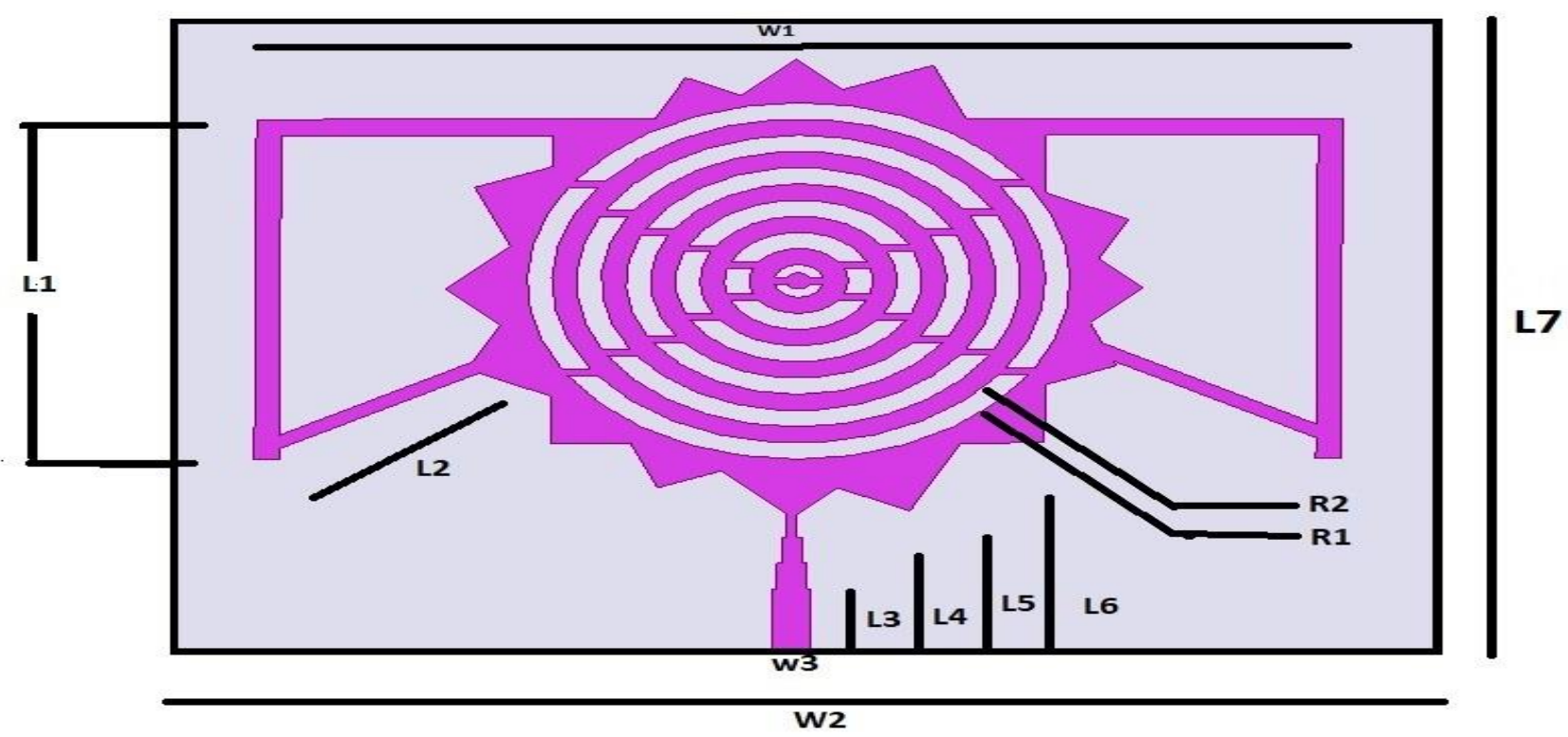

Figure 1: Microstrip patch antenna with a single patch

\subsection{Microstrip Patch Antenna with $2 \times 2$ Patch:}

The antenna is configured using the same single patch structure with the extension of $2 \times 2$, the antennas are arranged in the matrix form with two rows and two columns. The feed lines are drawn row-wise and connected in a column to match the impedance between the four single patch antennas. The antenna substrate is measured at $82 \times 115 \mathrm{~mm}$ with a $2 \times 30 \mathrm{~mm}$ of the feed line. The antenna is designed using the Rogers RT duroid 5880tm, with a relative permittivity of 2.2 .

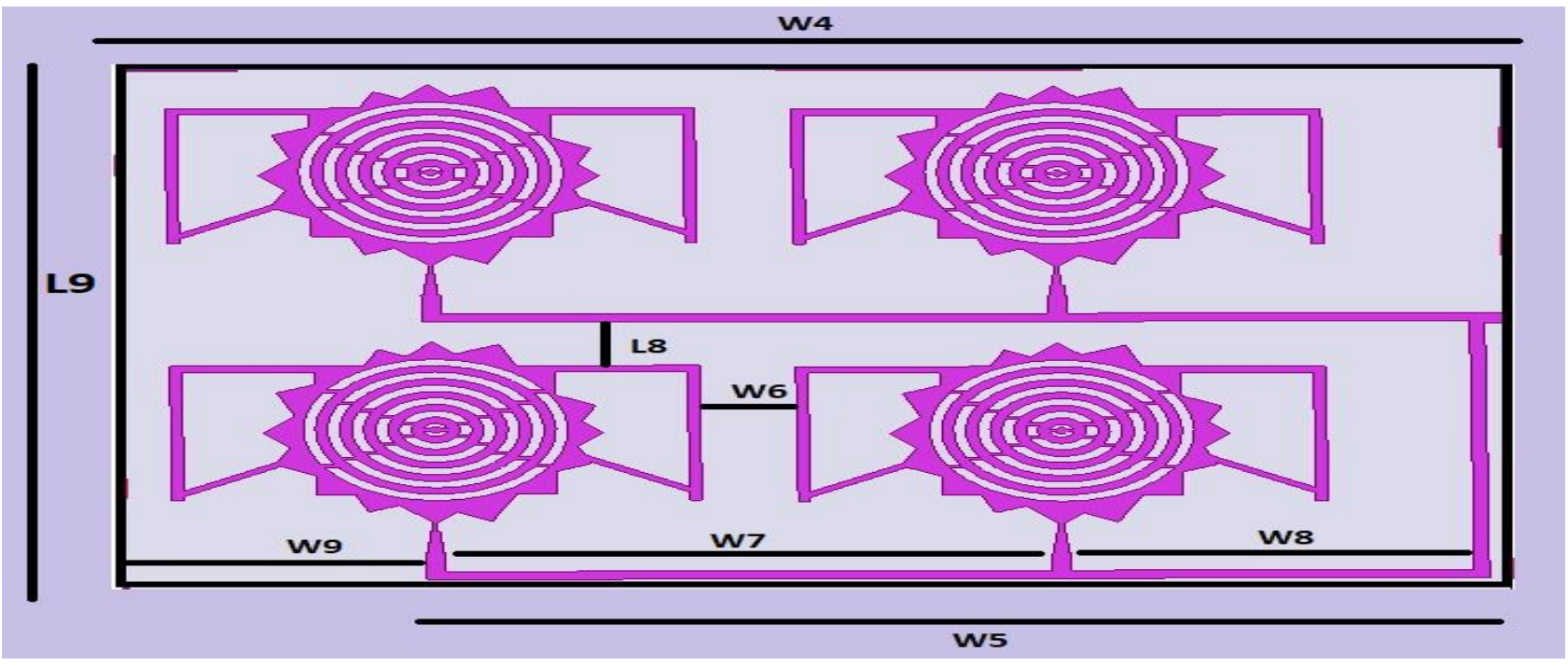


Figure 2: Microstrip patch antenna with $2 \times 2$ array

Table 2: Dimension of single patch and multi-patch antennas(dimensions in $\mathrm{mm}$ )

\begin{tabular}{|c|c|c|c|c|c|c|c|c|c|}
\hline $\mathbf{L 1}$ & $\mathbf{L 2}$ & $\mathbf{L 3}$ & $\mathbf{L 4}$ & $\mathbf{L 5}$ & $\mathbf{L 6}$ & $\mathbf{L 7}$ & $\mathbf{L 8}$ & $\mathbf{L 9}$ & $\mathbf{R 1}$ \\
\hline 21 & 8 & 4 & 5.5 & 7 & 8.5 & 39 & 7 & 82 & 10 \\
\hline $\mathbf{W 1}$ & $\mathbf{W 2}$ & $\mathbf{W 3}$ & $\mathbf{W 4}$ & $\mathbf{W 5}$ & $\mathbf{W 6}$ & $\mathbf{W 7}$ & $\mathbf{W 8}$ & $\mathbf{W 9}$ & $\mathbf{R 2}$ \\
\hline 44 & 52 & 1.6 & 115 & 90 & 8 & 50 & 33 & 25 & 9 \\
\hline
\end{tabular}

The antenna dimensions are calculated as per the circular patch with radius of $r$, and the mathematical formulation is as follows:

$$
\begin{aligned}
& \mathbf{R}=\operatorname{Qr} / \omega \mathrm{rC} \\
& \mathbf{L}_{1}=1 / \omega_{r}^{2} \mathbf{C}_{1} \\
& \mathbf{C}_{1}=\frac{L W \mathcal{L} 0 \mathcal{E} e}{2 h} \cos ^{2}\left(\prod \mathrm{x}_{0} / \mathrm{L}\right)
\end{aligned}
$$

in which $\mathrm{L}=$ Patch length, $\mathrm{W}=$ Patch width, $\mathrm{x}_{0}=$ feed point location, $\mathrm{h}=$ substrate thickness.

$$
\mathrm{Q}_{\mathrm{r}}=\frac{\boldsymbol{c} \sqrt{\epsilon e}}{\boldsymbol{f h}}
$$

where $\mathrm{f}=$ frequency of the designed antenna, $\mathrm{c}=$ light velocity, $\varepsilon_{\mathrm{e}}=$ effective permittivity of medium.

$$
\varepsilon_{\mathrm{e}}=\frac{\in r+1}{2}+\frac{\in r-1}{2}\left(1+\frac{12 h}{W}\right)^{-1 / 2}
$$

\section{Design Evolution of the proposed $2 \times 2$ patch antenna}

In the proposed design, 5 inner circles are loaded in the circular patch each decreasing continously by a factor of $1 \mathrm{~mm}$ and three stages are implemented where the antenna is first designed using a single patch, then the antenna is designed using a $1 \times 2$ patch format and finally the antenna is designed using $2 \times 2$ patch as shown in the figure 3 .

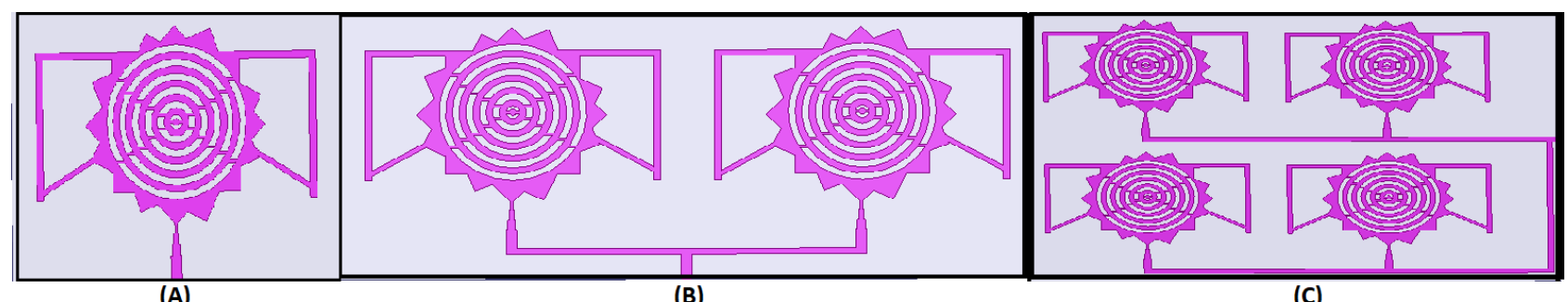

Figure 3:(A) Single patch antenna $(B) 1 \times 2$ patch antenna $(C) 2 \times 2$ patch antenna 
The iterations and number of circular cross sections are mentioned in Table 3 with the impedances of fractal antenna is shown in Figure 4.

Table 3: Comparison of number of slots for the designed antenna

\begin{tabular}{|l|l|}
\hline Iterations & Chakra Shape \\
\hline Nth Stage & $6 \times 2^{(\mathrm{n}-1)}$ Circular Slots \\
\hline $1^{\text {st }}$ Stage $($ single patch $)$ & $6 \times 2^{0}=6 \times 1=6$ \\
\hline $2^{\text {nd }}$ Stage $(1 \times 2$ patch $)$ & $6 \times 2^{1}=6 \times 2=12$ \\
\hline $3^{\text {rd }}$ Stage $(2 \times 2$ patch $)$ & $6 \times 2^{2}=6 \times 4=24$ \\
\hline
\end{tabular}
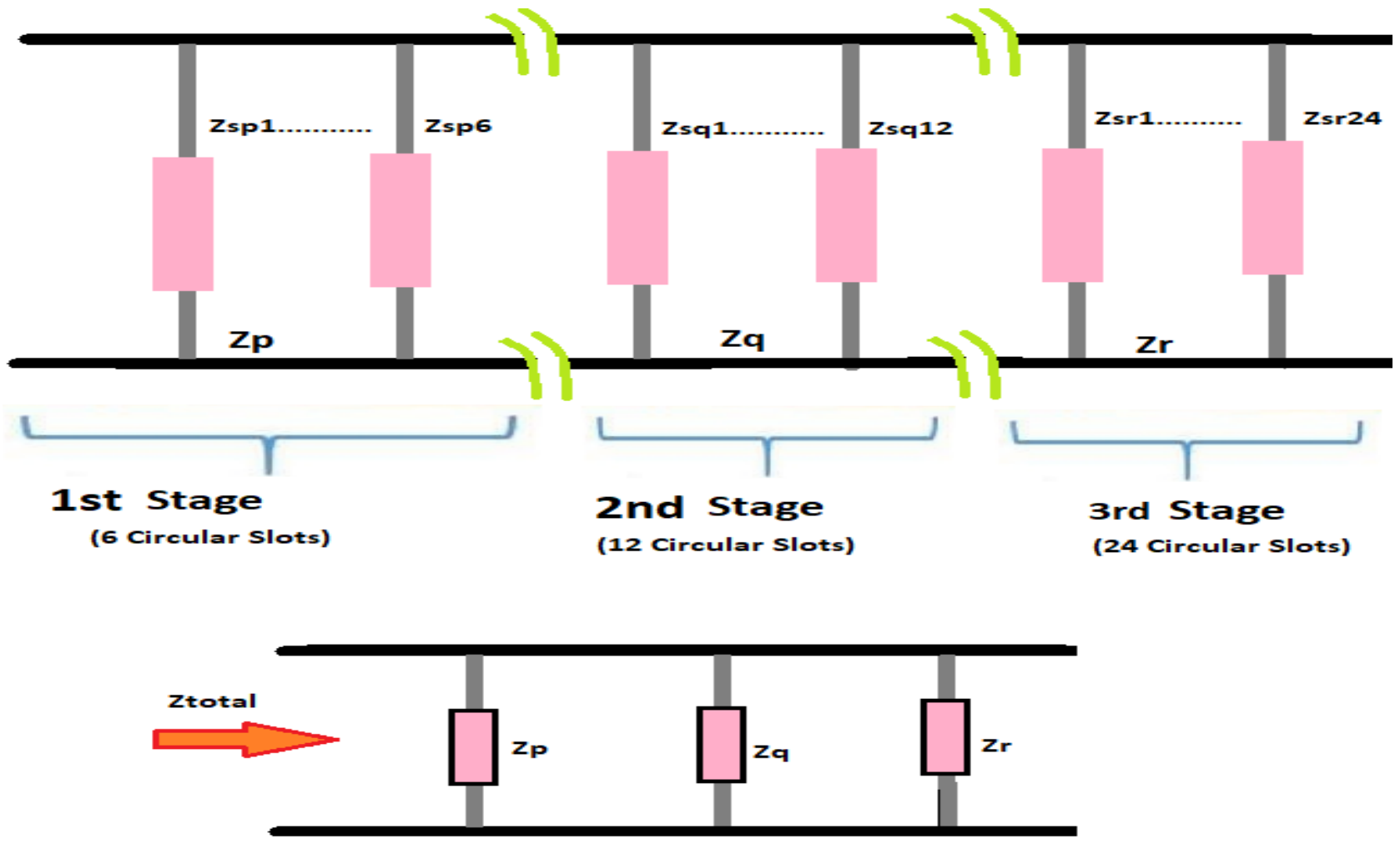

Fig4: Circuit Diagram of Designed Antenna

The equivalent input impedance of the chakra shaped fractal antenna with single, $1 \times 2$ and $2 \times 2$ patch are provided in equation 6 , as for single patch there are 6 circular slots, for $1 \times 2$ patch there are 12 circular slots and 24 for $2 \times 2$ patch respectively [8] .

$$
\mathrm{Z}_{\mathrm{total}}=\frac{1}{\frac{1}{Z p}+\frac{1}{Z q}+\frac{1}{Z r}} \quad=\frac{1}{\frac{6}{Z s p}+\frac{12}{Z s q}+\frac{24}{Z s r}}
$$

Where $\mathrm{Zp}, \mathrm{Zq}$ and $\mathrm{Zr}$ are the equivalent impedance of similar circular slots loaded on to the antenna of different stages and can be calculated as 
$\mathrm{Zp}=\frac{1}{\frac{1}{Z s p 1}+\cdots \frac{1}{Z s p 6}}=\frac{Z s p}{6} ; Z \operatorname{sp}=Z \operatorname{sp} 1 \ldots . .=Z \operatorname{sp6} ;\left(1^{\text {st }}\right.$ stage with six circular slots $)$

$\mathrm{Zq}=\frac{1}{\frac{1}{Z s q 1}+\cdots \frac{1}{Z s q 12}}=\frac{Z s q}{12} ; Z s q=Z s q 1 \ldots \ldots=Z s q 12 ;\left(2^{\text {nd }}\right.$ stage with twelve circular slots $)(8)$

$\mathrm{Zr}=\frac{1}{\frac{1}{Z s r 1}+\cdots \frac{1}{Z s r 24}}=\frac{Z s r}{24} ; Z s r=Z \operatorname{sr} 1 \ldots \ldots=Z \operatorname{sr} 24 ;\left(3^{\text {rd }}\right.$ stage with twenty four slots $)(9)$

The antenna performance parameters can be calculated using total input impedance for all the three stages combining as $\left(\mathrm{Z}_{\text {total }}\right)$

Reflection Coefficient, $\Gamma=\left(\frac{\text { Ztotal }-Z o}{\text { Ztotal }+Z 0}\right)$

\subsection{Parametric study of $S_{11}$ parameter for different antenna configurations}

The parametric investigations are performed to observe the variations of reflection coefficients for different design evolution stages. Figure 5 provides the parametric study of $S_{11}$ for all the designed antenna structures, single patch, $1 \times 2$ patch and $2 \times 2$ patch configurations. It can be observed that as the numbers of elements are increased, the reflection coefficient are reduced and number of resonating points have increased. So, with the suggested $2 \times 2$ patch array configuration, the antenna resonates at multiple bands with enhanced operating bandwidths.

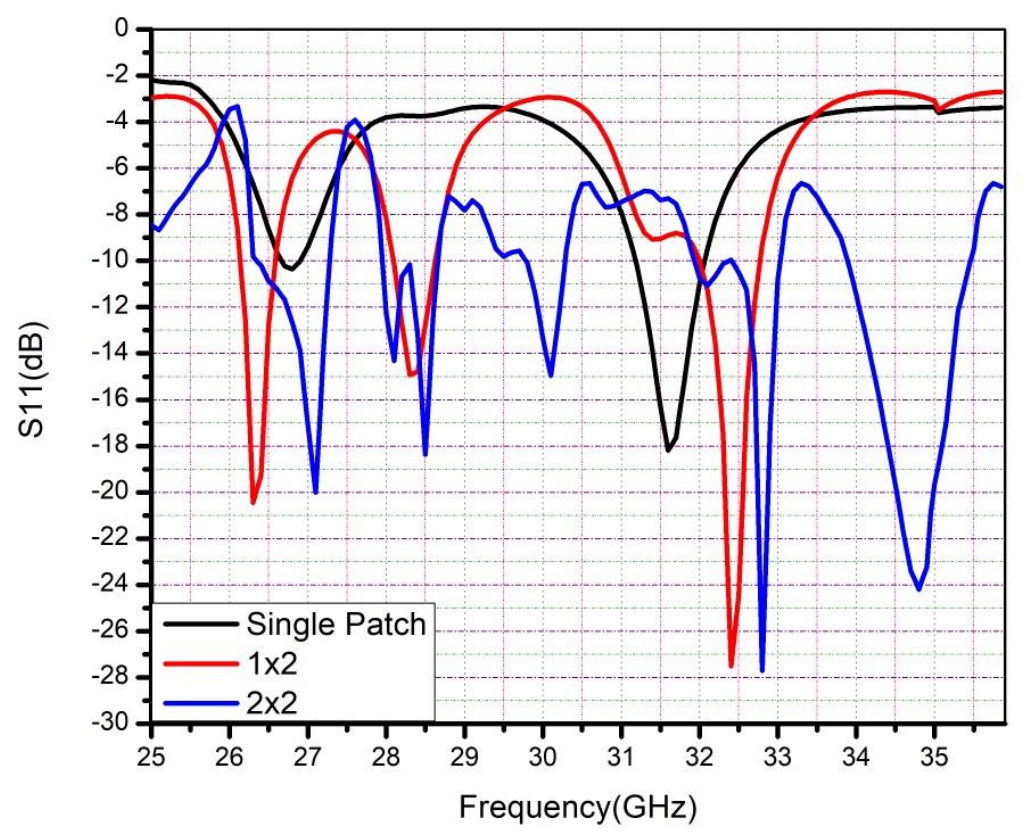

Figure 5: Parametric study of $S_{11}$ for single patch antenna, $1 \times 2$ patch antenna and $2 \times 2$ patch antenna

The design and analysis execution flowchart of the proposed $2 \times 2$ multi-patch antenna models is presented in Figure 6. 


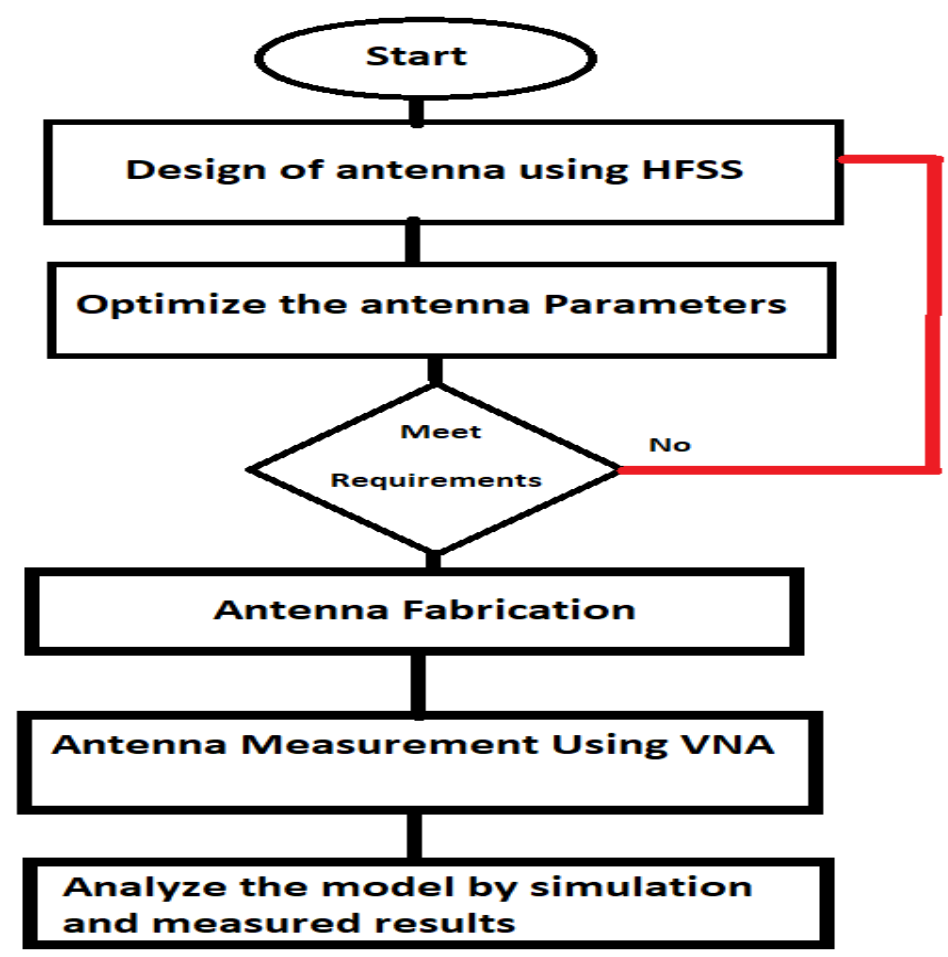

Figure 6: Detailed design and analysis flow chart of the designed antennas

\section{Results and Discussion}

\subsection{Simulation}

The simulation studies are performed using HFSS EM solver, with the operating frequency from $25 \mathrm{GHz}$ to $36 \mathrm{GHz}$ and the analysis has been carried out on single patch and multi-patch antenna separately. Figure 7 shows the surface current all over the patch, the electrical field is strong throughout the antenna and provides good stability, and radiates maximum energy which is received at the port. Maximum current distribution is available at the center of the proposed multi-patch antenna with high magnitude at the edges of the patch for the resonating frequency of $32.8 \mathrm{GHz}$.

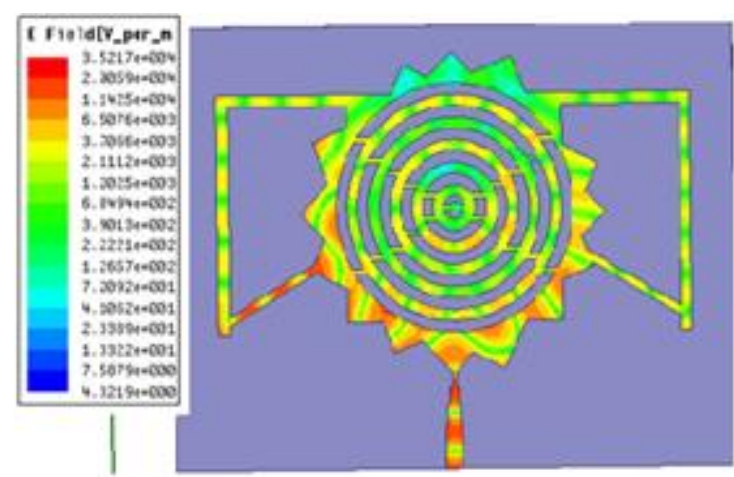

Single Patch

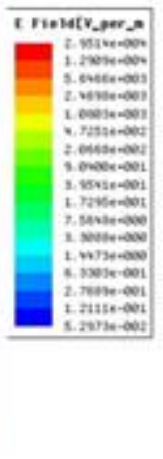

Multi Patch

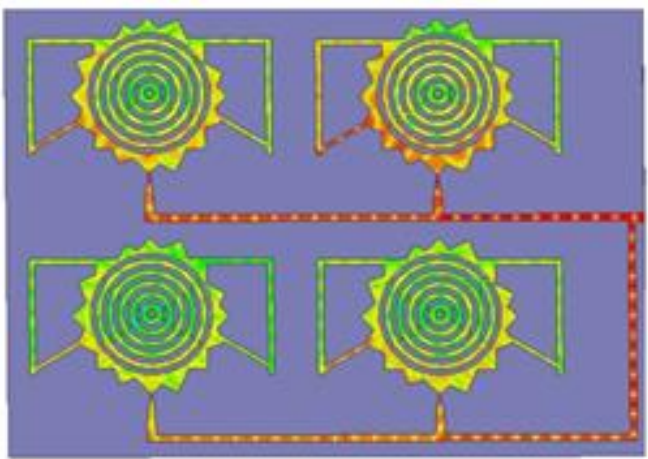

Figure 7: Surface Current on a single patch antenna at $31.35 \mathrm{GHz}$ and multi-patch antenna at $32.8 \mathrm{GHz}$ 
The antenna design is simulated for the frequency ranging from $25 \mathrm{GHz}$ to $36 \mathrm{GHz}$ and for the process of calculating the bandwidth, the first step is to find out the $S_{11}$ of both the antennas. Figure 8 represents the reflection coefficient vs. frequency characteristics of the single patch and multipatch antennas. It is evident from the portrayed figure that the suggested multi-patch antenna provides better performance and multiple resonating frequencies compared to the single patch antenna structure. As observed in Figure 8 (a), the single patch antenna provides dual band resonant characteristics as per observation below $-10 \mathrm{~dB}$ level of $\mathrm{S}_{11}$ parameter. However, very good reflection coefficient is observed at higher resonance with a highest attained value of $-18 \mathrm{~dB}$ at the resonant frequency of $31.6 \mathrm{GHz}$, As per Figure $8(\mathrm{~b})$, the multi-patch antenna provides penta band operation considering $S_{11} \leq-10 \mathrm{~dB}$ with significant bandwidths at each operating bands of $27.1 \mathrm{GHz}, 28.5 \mathrm{GHz}, 30.1 \mathrm{GHz}, 32.8 \mathrm{GHz}$ and $34.8 \mathrm{GHz}$ with the reflection coefficients of $20.01,-18.36,-14.96,-27.71$ and -24.19 respectively. The best value of reflection coefficient is recorded as $-27.71 \mathrm{~dB}$ at the frequency of $32.8 \mathrm{GHz}$ in the operating frequency.

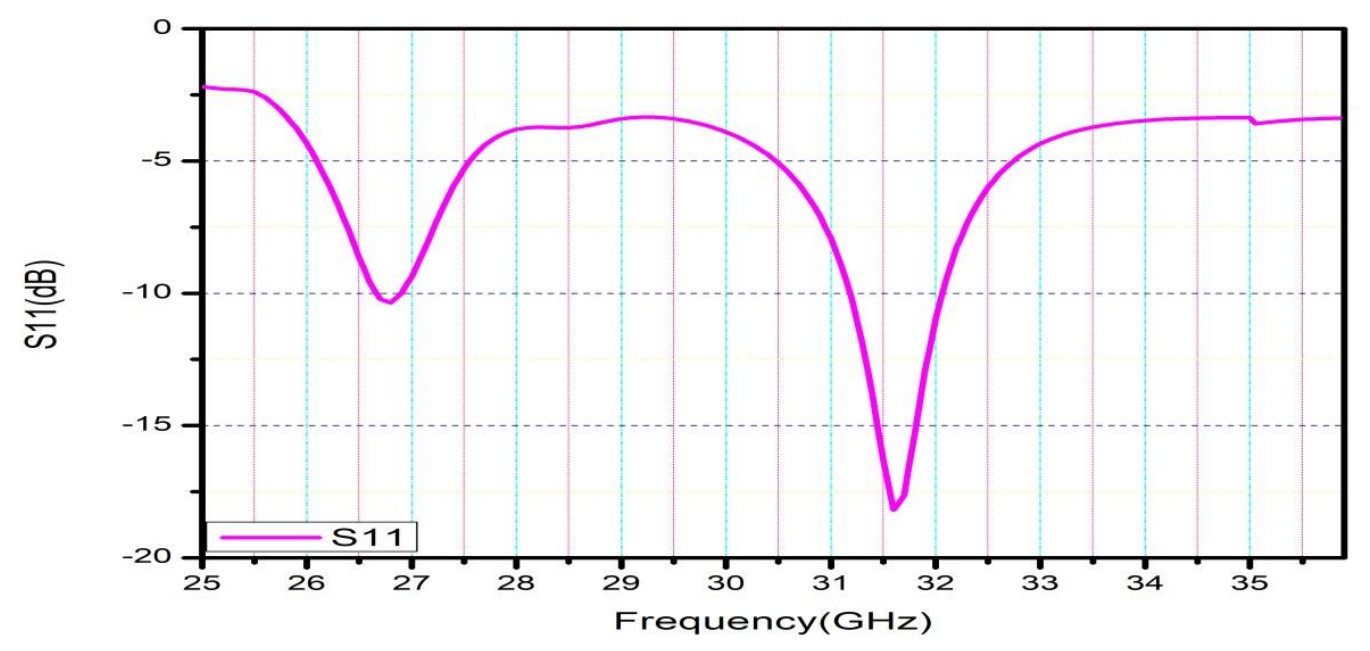

Figure 8a: Reflection coefficient of single patch antenna

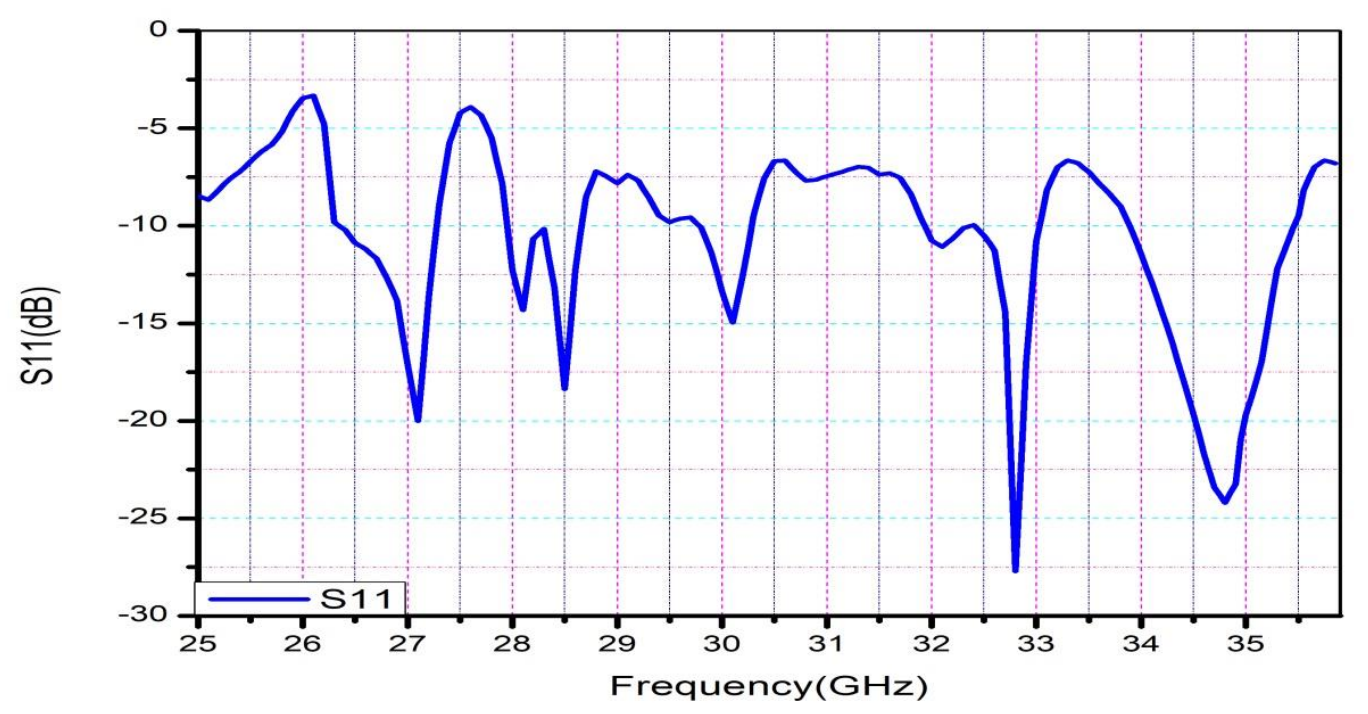

Figure 8b: Reflection coefficient of $2 \times 2$ multi-patch antenna 
The VSWR values are shown in Figure 9. As indicated in Figure 9 (a), VSWR of the single patch antenna is computed the values are within the maximum applicable limit of 4 in vehicular communication for the resonating points. The minimum VSWR for single patch antenna is observed at $31.6 \mathrm{GHz}$ with a value of 1.08 . On the other hand, due to the incorporated feed geometry, the proposed multi-patch antenna shows improvement in impedance matching and as a result minimum VSWR of 0.423 is obtained at $34.75 \mathrm{GHz}$. The acceptable VSWR confirms that well impedance matching the designed structures and ensure low mismatch losses associated with the suggested designed antenna models such that these antenna models can be used practically.

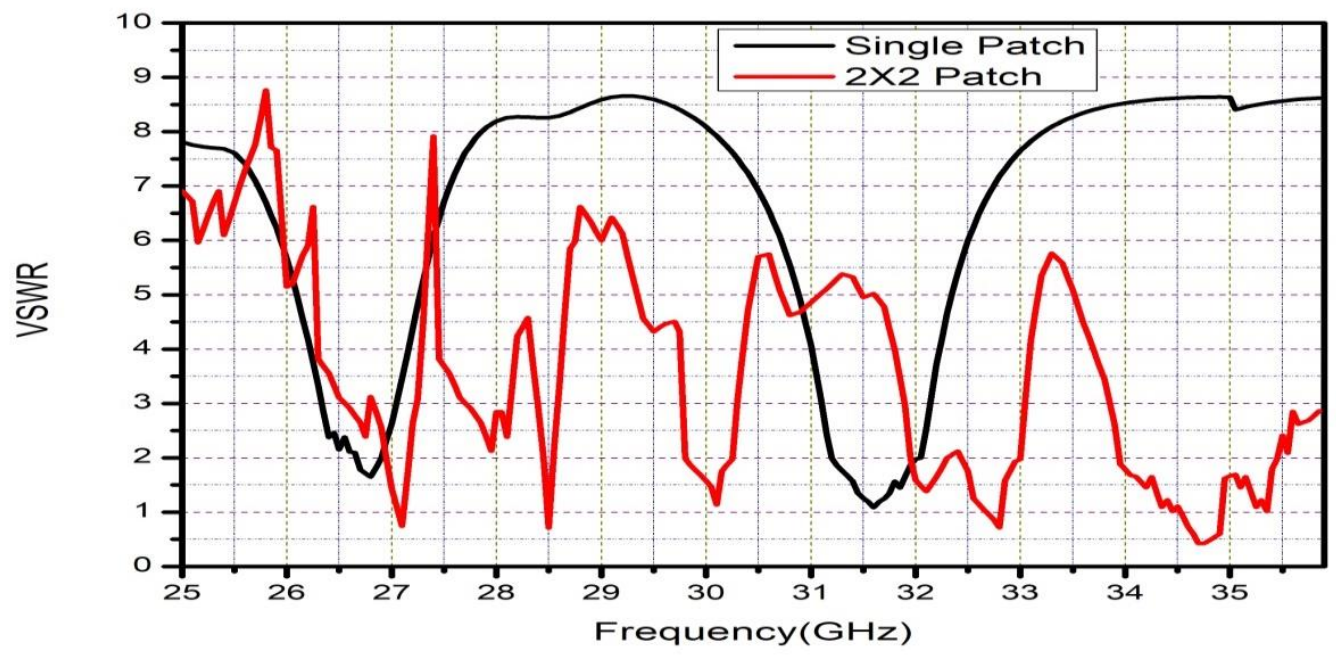

Figure 9: VSWR of single patch and $2 \times 2$ antennas

Figure 10 provides the radiation pattern of $2 \times 2$ antenna at operating bands of $27.1 \mathrm{GHz}, 28.5 \mathrm{GHz}$, $30.1 \mathrm{GHz}, 32.8 \mathrm{GHz}$ and $34.8 \mathrm{GHz}$ for both E-plane and H-plane of multi-patch antenna.
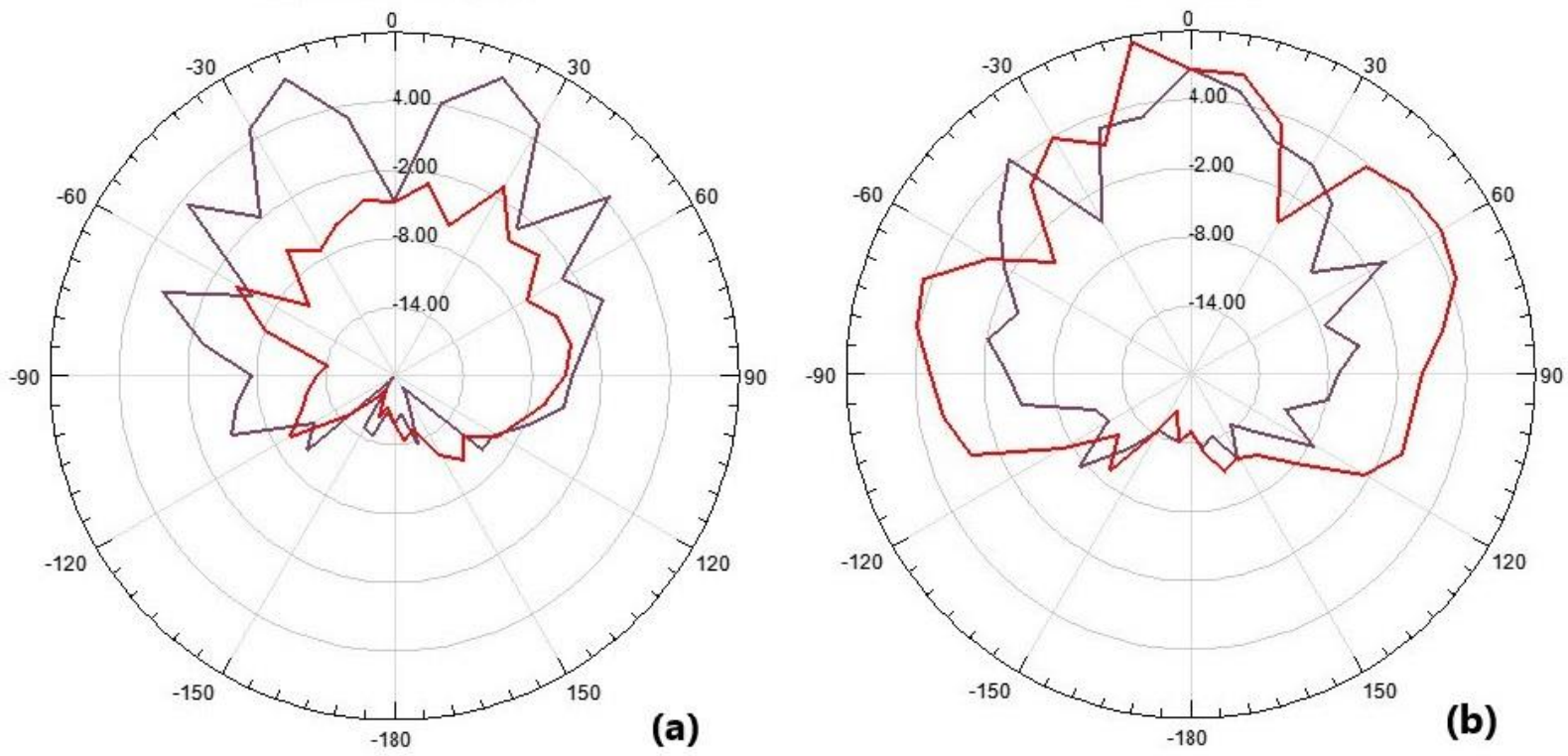

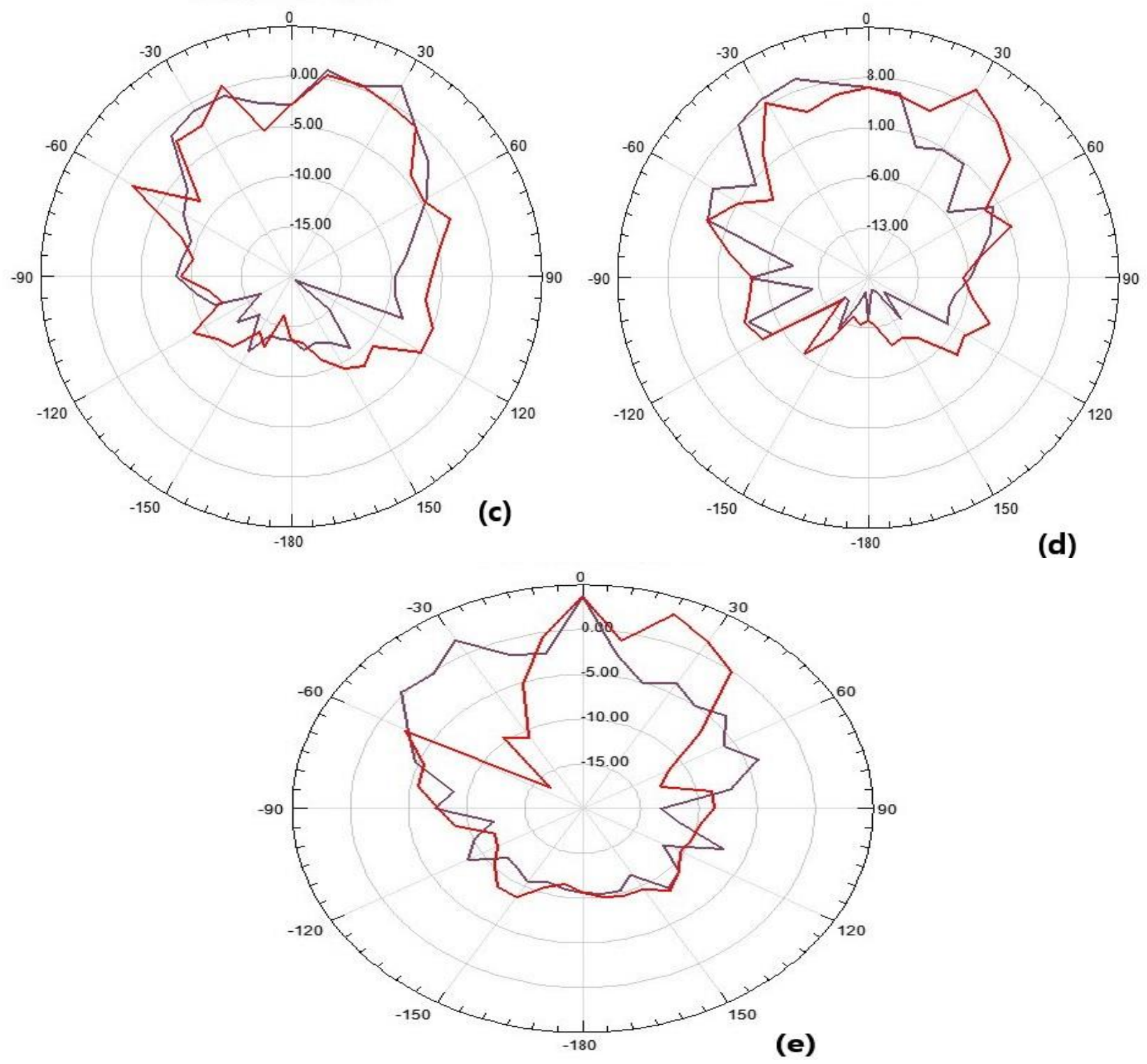

(d)

Figure 10: Radiation Patterns for E-plane represented in black and H-plane represented in red color of multi-patch antenna at a) $27.1 \mathrm{GHz}$ b) $28.5 \mathrm{GHz}$ c) $30.1 \mathrm{GHz}$ d) $32.8 \mathrm{GHz}$ e) $34.8 \mathrm{GHz}$

At 27.1Ghz, 7.63dB gain is achieved with the theta ranging from -20 degrees to +20 degrees with the phi value of 90 degrees, and at $28.5 \mathrm{GHz}, 9.43 \mathrm{~dB}$ gain is achieved with the theta ranging from -40 degrees to +40 degrees with phi value of 0 degrees. At $32.8 \mathrm{Ghz}, 9.17 \mathrm{~dB}$ gain is achieved with the theta ranging from -30 degrees to +30 degrees with the phi value of 0 degrees and at $34.8 \mathrm{GHz}$, $5.27 \mathrm{~dB}$ gain is achieved with the theta ranging from -30 degrees to +30 degrees with the phi value of 0 degrees. The achieved values implies that thee radiation pattern is best suitable for vehicular communication as it is spread out in forward directions and for moving vehicles the radiation should be towards the target with at least 20 degrees[17] and the proposed design is suitable with a range of at least 40 degrees overall .

Figure 11 provides the details about total gain with the primary sweep of frequency at theta and phi at zero degrees. The gain of the single patch antenna reaches the maximum gain of $8.2 \mathrm{~dB}$, and for 
most of the frequency range, the gain is greater than or equal to $3 \mathrm{~dB}$. The range starts from $25 \mathrm{GHz}$ and stays greater than $3 \mathrm{~dB}$ till $34.5 \mathrm{GHz}$. The gain of the multi-patch antenna reaches the maximum gain of $6.72 \mathrm{~dB}$ at resonating frequency of $32.8 \mathrm{GHz}$ and $6.69 \mathrm{~dB}$ at $28.5 \mathrm{GHz}$ respectively.

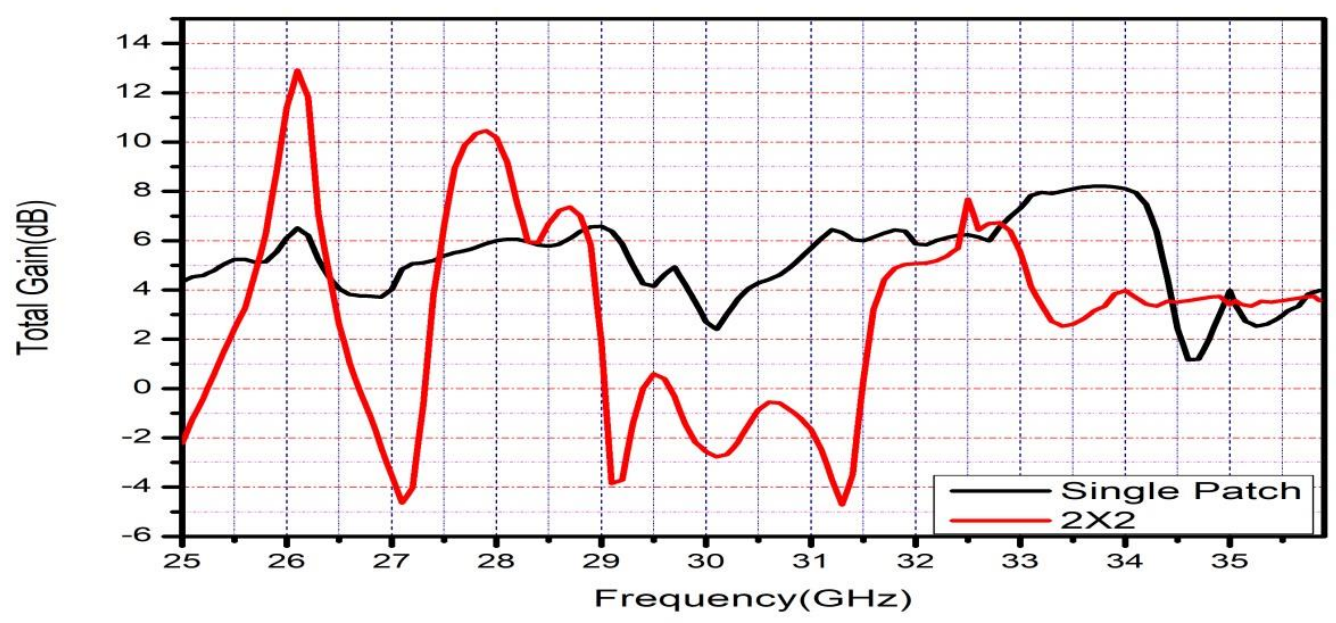

Figure 11: Total Gain of single patch and $2 \times 2$ antennas

\subsection{Fabrication and Measured results:}

The process for fabrication starts with exporting both patch and ground separately in the form of $\mathrm{dxf}$ files by keeping $\mathrm{z}$ axis as zero and dip trace software is used to combine both the patch and ground as single entity and then exported with an extension used is grb. This file is then opened in eagle software which is used to interface the single-sided CNC machine for fabrication which consist the precision of $95 \%$ efficiency and the material used for fabrication is Rogers RT duroid 5880tm. The time required for fabrication depends on the layers of antenna and the structure of patch. The proposed antenna took around 60 minutes for fabrication. Then the fabricated antenna models are connected with an SMA connector. The prototypes of the fabricated antennas are shown in Figure 12.

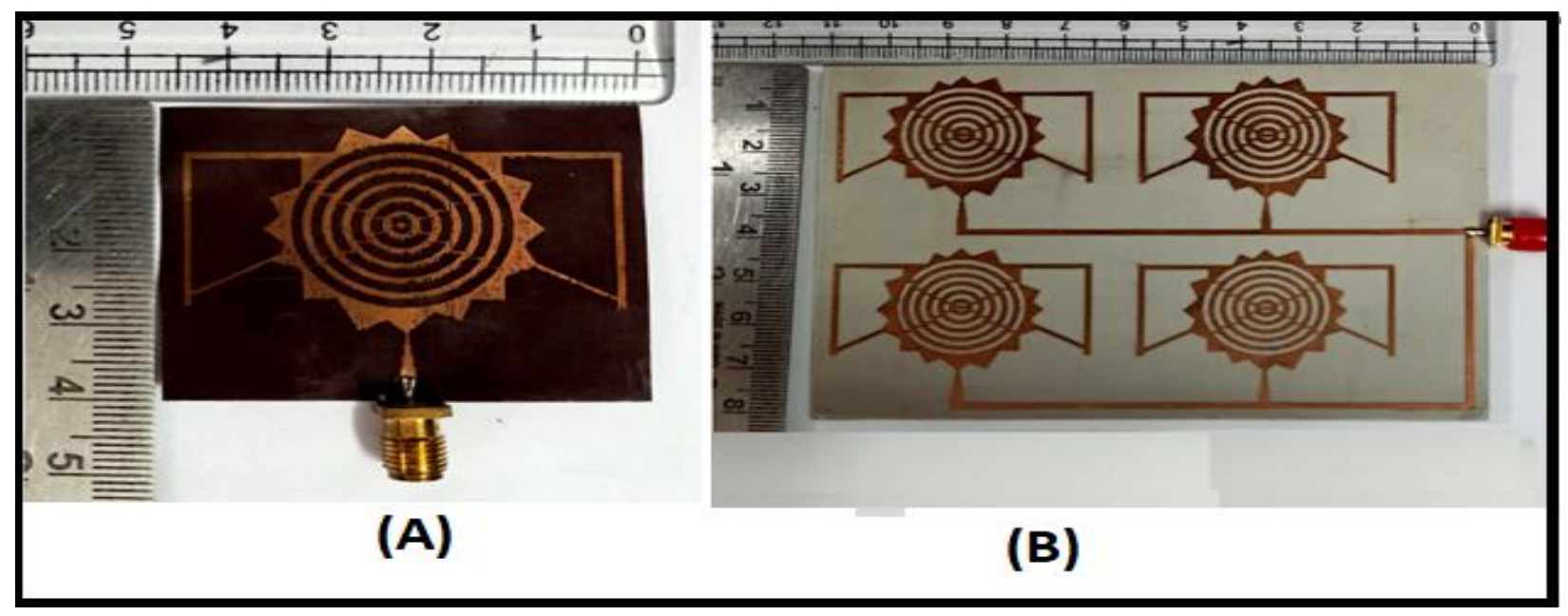

Figure 12: Fabrication of a) single patch b) multi-patch antenna 
The antenna after fabrication is tested under an experimental confined laboratory with a highly précised Vector Network Analyzer of Agilent Technologies N5247A with a range of $1 \mathrm{GHz}$ to $50 \mathrm{GHz}$ with both $1 \mathrm{~dB}$ and $2 \mathrm{~dB}$ sweep which is very much helpful for the futuristic frequencies. Figure 13 provides the snapshot of the measurement set up of antennas connected with VNA. The simulated and measured values are compared to provide information regarding the deviation of obtained results. The comparisons of measured and simulated $S_{11}$ parameters for the single patch antenna and proposed array antenna are shown in Figures 14 and 15, respectively. The detailed results are summarized in Table 4 . The measured and simulated $S_{11}$ results are almost similar and the array antenna with multi-patch elements possesses better results compared to the single patch and the performance has improved in reflection coefficient, number of operating bands, and bandwidth.

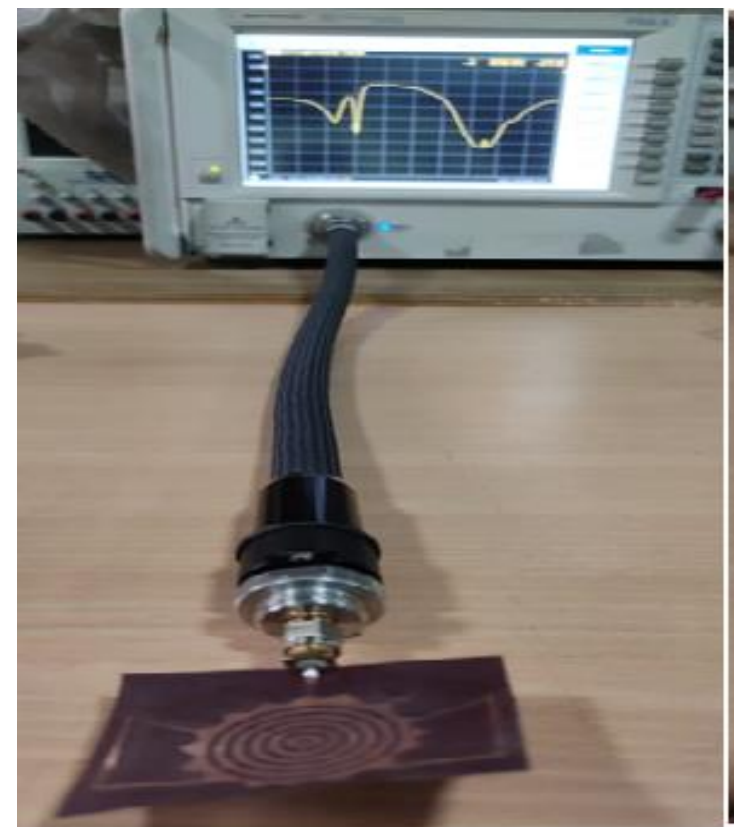

(a)

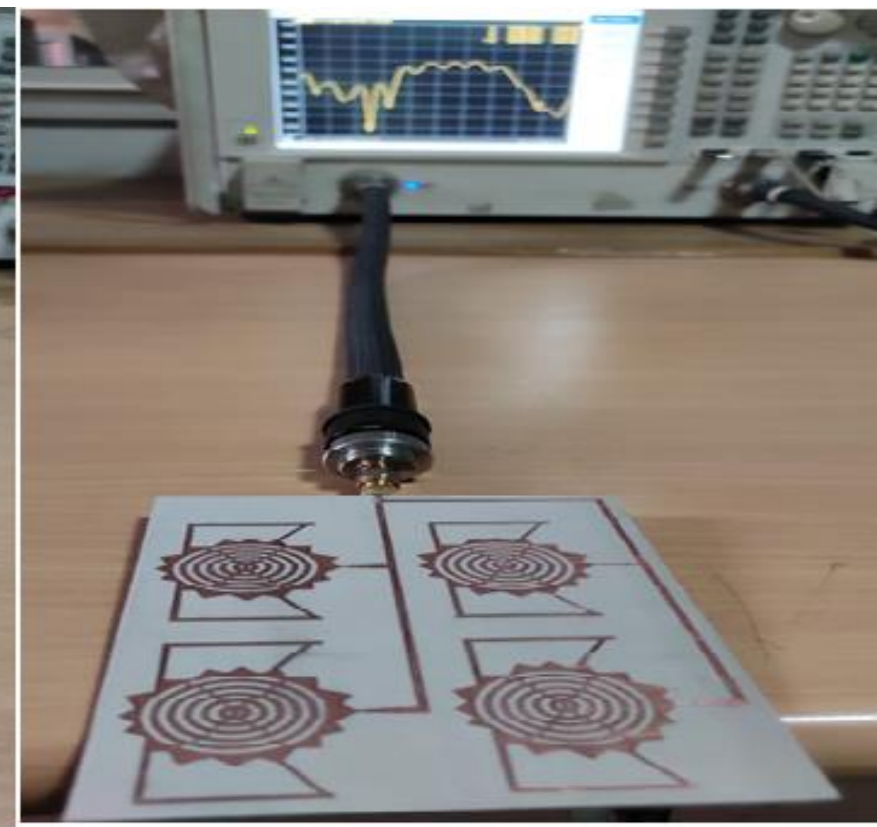

(b)

Figure 13: Testing of a) Single patch antenna b) multi-patch antenna

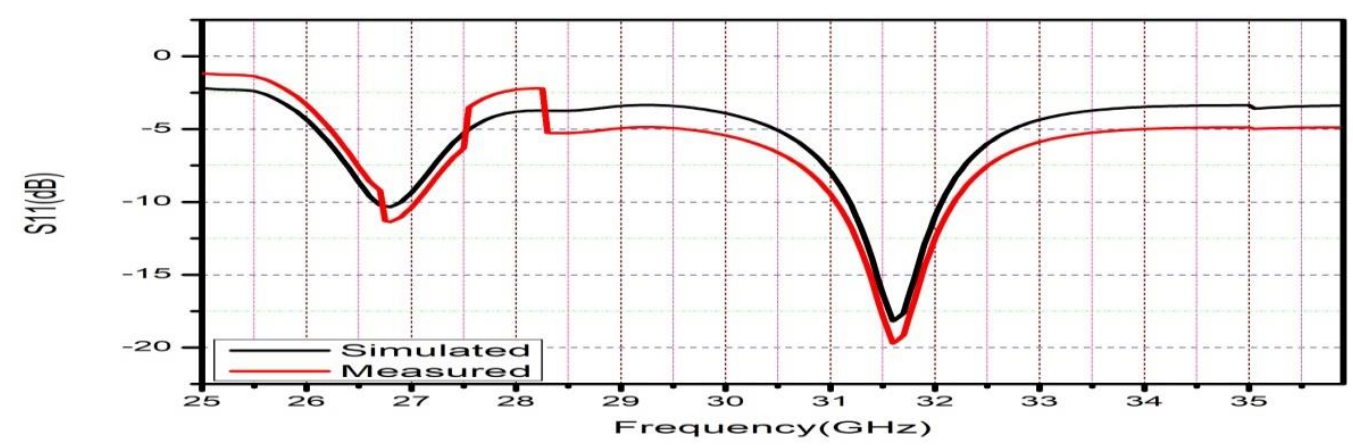

Figure 14: Comparison of measured and simulated $S_{11}$ of the single patch 


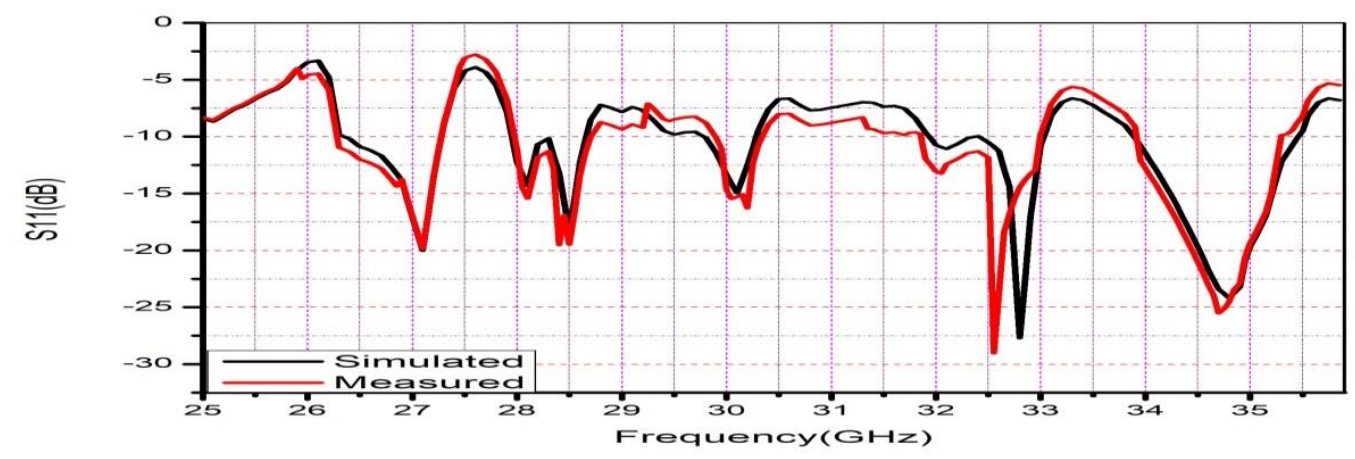

Figure 15: Comparison of measured and simulated $S_{11}$ of proposed multi-patch antenna

Table 4: Results of the single patch and multi-patch antenna.

\begin{tabular}{|c|c|c|c|c|c|c|c|}
\hline \multicolumn{4}{|c|}{ Simulated S11(Single Patch) } & \multicolumn{4}{|c|}{ Measured S11(Single Patch) } \\
\hline $\mathbf{f}_{L}(\mathbf{G H z})$ & $\mathbf{f}_{\mathrm{H}}(\mathbf{G H z})$ & $\mathbf{f}_{\mathbf{c}}(\mathbf{G H z})$ & BW(MHz) & $\mathbf{f}_{\mathrm{L}}(\mathrm{GHz})$ & $\mathbf{f}_{H}(\mathbf{G H z})$ & $\mathbf{f}_{\mathbf{c}}(\mathbf{G H z})$ & BW(MHz) \\
\hline \multirow[t]{2}{*}{29.35} & 32.65 & 31.35 & 3300 & 25 & 26.7 & 25.3 & 1700 \\
\hline & & & & 31.1 & 32.15 & 31.6 & 1050 \\
\hline \multicolumn{3}{|c|}{ Total Simulated Bandwidth } & $3.3 \mathrm{GHz}$ & \multicolumn{3}{|c|}{ Total Measured Bandwidth } & $2.75 \mathrm{GHz}$ \\
\hline \multicolumn{4}{|c|}{ Simulated S11(Multi-Patch) } & \multicolumn{4}{|c|}{ Measured S11(Mult- Patch) } \\
\hline $\mathbf{f}_{\mathrm{L}}(\mathrm{GHz})$ & $\mathbf{f}_{\mathbf{H}}(\mathbf{G H z})$ & $\mathbf{f}_{\mathbf{c}}(\mathbf{G H z})$ & BW(GHz) & $\mathbf{f}_{\mathrm{L}}(\mathbf{G H z})$ & $\mathbf{f}_{\mathbf{H}}(\mathbf{G H z})$ & $\mathbf{f}_{\mathbf{c}}(\mathbf{G H z})$ & BW(GHz) \\
\hline 26.35 & 27.25 & 27.1 & 0.9 & 26.3 & 27.25 & 27.05 & 0.95 \\
\hline 27.95 & 28.65 & 28.5 & 0.7 & 28 & 28.7 & 28.4 & 0.7 \\
\hline 29.8 & 30.25 & 30.1 & 0.45 & 29.9 & 30.3 & 30.05 & 0.4 \\
\hline 31.95 & 33 & 32.8 & 1.05 & 31.9 & 32.95 & 32.55 & 1.05 \\
\hline 33.9 & 35.45 & 34.8 & 1.55 & 33.95 & 35.25 & 34.7 & 1.3 \\
\hline \multicolumn{3}{|c|}{ Total Simulated Bandwidth } & $4.65 \mathrm{GHz}$ & \multicolumn{3}{|c|}{ Total Measured Bandwidth } & $4.4 \mathrm{GHz}$ \\
\hline
\end{tabular}

The table 4 provides the comparison between the simulated and measured $\mathrm{S}_{11}$ for both the single patch and multi-patch antenna. It can be concluded that due to the suggested array configuration, the antenna operates at more number of distinct operating bands with enhanced impedance bandwidths. In fact, the number of resonating frequencies has increased from two to five which makes the proposed array configuration suitable for multiple applications at the lower band spectrum of the upcoming $5 \mathrm{G}$ technology.

Table 5 provides a detailed comparison between the proposed antennas and work carried out by various researchers under fractal antennas, $5 \mathrm{G}$ and multiband applications. The $2 \times 2$ antenna achieved penta bands in the frequency ranging $25 \mathrm{GHz}$ to $36 \mathrm{GHz}$, and a combined simulated bandwidth of $4650 \mathrm{MHz}$ with a peak gain of $6.72 \mathrm{~dB}$. The proposed design is able to achieve higher bandwidths compare to other models but unable to enhance the total gain of the antenna but the gain is in acceptable range. This comparison clearly indicates that the proposed antenna performance is better in the area of bandwidth and good standing wave ratio compare to the antennas provided as reference. 
Table 5: Comparison between the proposed design model and other antennas design

\begin{tabular}{|c|c|c|c|c|c|c|}
\hline Reference & $\begin{array}{c}\text { Antenna } \\
\text { Dimension }\end{array}$ & Substrate used & $\begin{array}{c}\text { Operating band } \\
(\mathbf{G H z})\end{array}$ & $\begin{array}{c}\text { Bandwidth } \\
\text { (MHz) }\end{array}$ & $\begin{array}{l}\text { Peak } \\
\text { Gain } \\
\text { (dB) }\end{array}$ & $\begin{array}{c}\text { Minimum } \\
\text { VSWR }\end{array}$ \\
\hline $\begin{array}{l}\text { S. Patil et al., } \\
\text { [12] }\end{array}$ & $140 \times 88 \times 3.3$ & $\begin{array}{l}\text { Rogers } \\
\text { RT/duroid } \\
\text { 5880tm }\end{array}$ & $\begin{array}{c}0.5 \mathrm{GHz}-1.1 \mathrm{GHz}, \\
3.6 \mathrm{GHz}-3.95 \mathrm{GHz}, \\
5.25 \mathrm{GHz}-5.85 \mathrm{GHz}, \\
7.35 \mathrm{GHz}-8.1 \mathrm{GHz}, \\
9.65 \mathrm{GHz}-10.25 \mathrm{GHz} \\
11.03 \mathrm{GHz}-12 \mathrm{GHz} \\
\end{array}$ & $2400 \mathrm{MHz}$ & $6.9 \mathrm{~dB}$ & 1.4 \\
\hline $\begin{array}{l}\text { Fadhel et al., } \\
\text { [13] }\end{array}$ & $32 \times 36 \times 1.6$ & $\begin{array}{l}\text { Rogers } \\
\text { RT/duroid } \\
\text { 5880tm }\end{array}$ & $\begin{array}{l}\text { 4.0GHz-4.65GHz, } \\
\text { 5.67GHz-6.1GHz, } \\
10.35 \mathrm{GHz}-11.0 \mathrm{GHz}\end{array}$ & $1200 \mathrm{MHz}$ & $7.32 \mathrm{~dB}$ & 1.21 \\
\hline S Das et al., [14] & $\begin{array}{c}26 \times 30 \times \\
1.53\end{array}$ & FR4_Epoxy & $\begin{array}{l}3 \mathrm{GHz}-8 \mathrm{GHz}, \\
8.92 \mathrm{GHz}-10.65 \mathrm{GHz}, \\
18 \mathrm{GHz}-22 \mathrm{GHz}, \\
28.5 \mathrm{GHz}-30 \mathrm{GHz}\end{array}$ & $1600 \mathrm{MHz}$ & $9.56 \mathrm{~dB}$ & 1.22 \\
\hline $\begin{array}{l}\text { N. T. Atanasov et } \\
\text { al., [15] }\end{array}$ & $\begin{array}{c}120 \times 120 \times \\
4.3\end{array}$ & $\begin{array}{l}\text { Rogers } \\
\text { RT/duroid } \\
\text { 5880tm } \\
\end{array}$ & $2.36 \mathrm{GHz}-2.50 \mathrm{GHz}$ & $130 \mathrm{MHz}$ & $10.68 \mathrm{~dB}$ & 0.98 \\
\hline $\begin{array}{l}\text { J. B. Benavides } \\
\text { et al., [16] }\end{array}$ & $150 \times 150 \times 4$ & $\begin{array}{l}\text { Rogers } \\
\text { RT/duroid } \\
\text { 5880tm }\end{array}$ & $\begin{array}{l}9.8 \mathrm{GHz}-10.36 \mathrm{GHz} \\
13.6 \mathrm{GHz}-15 \mathrm{GHz}\end{array}$ & $2360 \mathrm{MHz}$ & $8.35 \mathrm{~dB}$ & 1.01 \\
\hline Zhu et al., [17] & $\begin{array}{c}42 \times 33 \times \\
1.58\end{array}$ & FR4_Epoxy & $\begin{array}{l}24.5 \mathrm{GHz}-26.32 \mathrm{GHz} \\
28.1 \mathrm{GHz}-19.36 \mathrm{GHz}, \\
31.2 \mathrm{GHz}-32.13 \mathrm{GHz} \text {. }\end{array}$ & $3300 \mathrm{MHz}$ & $7.45 \mathrm{~dB}$ & 1.21 \\
\hline S. Velan et al[18] & $\begin{array}{c}64.4 \times 53.7 \times \\
3.94\end{array}$ & $\begin{array}{c}\text { Rogers } \\
\text { RT/duroid } \\
\text { 5880tm } \\
\end{array}$ & $\begin{array}{l}28 \mathrm{GHz}-29.17 \mathrm{GHz} \\
31.3 \mathrm{GHz}-32.5 \mathrm{GHz}\end{array}$ & $1200 \mathrm{MHz}$ & $8.16 \mathrm{~dB}$ & 0.87 \\
\hline $\begin{array}{l}\text { X. Zhu et } \\
\text { al..,[19] }\end{array}$ & $\begin{array}{c}59.9 \times 59.9 \times \\
3.7\end{array}$ & $\begin{array}{l}\text { Electromagnetic } \\
\text { band gap (EBG) } \\
\text { structure }\end{array}$ & $\begin{array}{l}18.5 \mathrm{GHz}-19.28 \mathrm{GHz} \\
22.3 \mathrm{GHz}-22.95 \mathrm{GHz}, \\
23.6 \mathrm{GHz}-24.3 \mathrm{GHz}\end{array}$ & $1890 \mathrm{MHz}$ & $6.12 \mathrm{~dB}$ & 1.01 \\
\hline $\begin{array}{l}\text { S. Agneessens } \\
\text { et.al..,[20] }\end{array}$ & $\begin{array}{c}40 \times 40 \times \\
0.503\end{array}$ & $\begin{array}{l}\text { non-conductive } \\
\text { textile material }\end{array}$ & $\begin{array}{l}24.6 \mathrm{GHz}-25.32 \mathrm{GHz} \\
26.8 \mathrm{GHz}-27.35 \mathrm{GHz}\end{array}$ & $3500 \mathrm{MHz}$ & $6.54 \mathrm{~dB}$ & 0.75 \\
\hline $\begin{array}{c}\text { Proposed } \\
\text { Design-single } \\
\text { patch }\end{array}$ & $\begin{array}{c}39 \times 48 \times \\
0.52\end{array}$ & $\begin{array}{l}\text { Rogers } \\
\text { RT/duroid } \\
\text { 5880tm }\end{array}$ & $29.35 \mathrm{GHz}-32.65$ & 3300MHz & $5.6 \mathrm{~dB}$ & 1.08 \\
\hline $\begin{array}{c}\text { Proposed } \\
\text { Design:multi- } \\
\text { patch antenna }\end{array}$ & $\begin{array}{c}82 \times 115 \times \\
0.52\end{array}$ & $\begin{array}{l}\text { Rogers } \\
\text { RT/duroid } \\
\text { 5880tm }\end{array}$ & $\begin{array}{c}26.35 \mathrm{GHz}-27.25 \mathrm{GHz}, \\
27.95 \mathrm{GHz}-28.65 \mathrm{GHz}, \\
\text { 29.8GHz-30.25GHz, } \\
\text { 31.95GHz-33GHz, } \\
33.9 \mathrm{GHz}-35 \mathrm{GHz} .\end{array}$ & $4650 \mathrm{MHz}$ & $6.72 \mathrm{~dB}$ & 0.423 \\
\hline
\end{tabular}


Conclusion: A single patch and $2 \times 2$ patch fractal geometry based chakra-shaped microstrip patch antenna for vehicular communications is investigated and discussed in this paper. The $2 \times 2$ patch covers five operating bands in the range of $25 \mathrm{GHz}$ to $36 \mathrm{GHz}$. The gain of the antenna reaches the maximum gain of $6.72 \mathrm{~dB}$ at resonating frequency of $32.8 \mathrm{GHz}$ and $6.69 \mathrm{~dB}$ at $28.5 \mathrm{GHz}$ respectively. The reflection coefficients of $-20.01,-18.36,-14.96,-27.71$ and -24.19 respectively achieved at operating bands of $27.1 \mathrm{GHz}, 28.5 \mathrm{GHz}, 30.1 \mathrm{GHz}, 32.8 \mathrm{GHz}$ and $34.8 \mathrm{GHz}$. Maximum current distribution is achieved at the center of the proposed multi-patch array antenna with high magnitude at the edges of the patch for the resonating frequency of 32.8GHz.A good agreement between the experimental and simulated results justifies the suitability of proposed antenna for vehicular communications as it needs multi band antennas for its communication with good peak gain and better bandwidth. The proposed antenna has enhanced the overall bandwidth to $4650 \mathrm{MHz}$ in the $5 \mathrm{G}$ proposed lower band spectrums for vehicular communications.

\section{Acknowledgment}

This paper and the research behind it would not have been possible without the exceptional support of my supervisor. His enthusiasm, knowledge, and exacting attention to detail have been an inspiration and kept my work on track.. We thank our colleagues from Lovely Professional University, Phagwara, Punjab, India who provided insight and expertise that greatly assisted the research. We are also immensely grateful to all our friends for their comments on the preparation of the manuscript, although any errors are our own and should not tarnish the reputations of these esteemed persons.

\section{Conflict of Interest}

The authors certify that they have no affiliations with or involvement in any organization or entity with any financial interest (such as honoraria; educational grants; participation in speakers' bureaus; membership, employment, consultancies, stock ownership, or other equity interest; and expert testimony or patentlicensing arrangements), or non-financial interest (such as personal or professional relationships, affiliations, knowledge or beliefs) in the subject matter or materials discussed in this manuscript.

\section{References:}

[1] Maciej Rogalski, Security assessment of suppliers of telecommunications infrastructure for the provision of services in 5G technology,Computer Law \& Security Review, Volume 41, 2021, 105556, ISSN 0267-3649, https://doi.org/10.1016/j.clsr.2021.105556.

[2] Haotong Cao, Yue Hu, Longxiang Yang, Towards intelligent virtual resource allocation in UAVs-assisted 5G networks, Computer Networks, Volume 185, 2021,107660,ISSN 1389-1286, https://doi.org/10.1016/j.comnet.2020.107660.

[3] Moo-Woong Jeong, Jong Yeol Ryu, Seong Hwan Kim, Woongsup Lee, Tae-Won Ban, A completely distributed transmission algorithm for mobile device-to-device caching networks, Computers \& Electrical Engineering, Volume 87, 2020, 106803, ISSN 0045-7906, https://doi.org/10.1016/j.compeleceng.2020.106803.

[4] Hani J. Kbashi, Vishal Sharma, Sergey Sergeyev, Dual-wavelength fiber-laser-based transmission of millimeter waves for 5G-supported Radio-over-Fiber (RoF) links, Optical Fiber Technology, Volume 65, 2021, 102588, ISSN 1068-5200, https://doi.org/10.1016/j.yofte.2021.102588.

[5] Kai Zhan, Sports and health big data system based on 5G network and Internet of Things system,

Microprocessors and Microsystems, Volume 80, 2021, 103363, ISSN 0141-9331,

https://doi.org/10.1016/j.micpro.2020.103363. 
[6] Rahim A., Malik P.K., Sankar Ponnapalli V.A. (2020) State of the Art: A Review on Vehicular Communications, Impact of 5G, Fractal Antennas for Future Communication. In: Singh P., Pawłowski W., Tanwar S., Kumar N., Rodrigues J., Obaidat M. (eds) Proceedings of First International Conference on Computing, Communications, and Cyber-Security (IC4S 2019). Lecture Notes in Networks and Systems, vol 121. Springer, Singapore. https://doi.org/10.1007/978-981-15-3369-3_1

[7] Rahim A, Mallik PK, Ponnapalli VAS. Fractal antenna design for overtaking on highways in 5G vehicular communication ad-hoc networks environment. Int J Eng Adv Technol. 2019; 9(1S6): 157- 160.

https://doi.org/10.35940/ijeat.A1031.1291S619.

[8] Xiaotong Li, Ruiting Zhou, Ying-Jun Angela Zhang, Lei Jiao, Zongpeng Li, Smart vehicular communication via 5G mmWaves, Computer Networks, Volume 172, 2020, 107173, ISSN 1389-1286,

https://doi.org/10.1016/j.comnet.2020.107173.

[9] Lin Li, Real time auxiliary data mining method for wireless communication mechanism optimization based on Internet of things system, Computer Communications, Volume 160, 2020, Pages 333-341, ISSN 0140-3664, https://doi.org/10.1016/j.comcom.2020.06.021.

[10] Pranav Kumar Singh, Sunit Kumar Nandi, Sukumar Nandi, A tutorial survey on vehicular communication state of the art, and future research directions, Vehicular Communications, Volume 18, 2019, 100164, ISSN 2214-2096, https://doi.org/10.1016/j.vehcom.2019.100164.

[11] Abdul Rahim, Praveen Kumar Malik, Analysis and Design of Fractal Antenna for Efficient Communication network in Vehicular model, Sustainable Computing: Informatics and Systems, 2021, 100586, ISSN 2210-5379, https://doi.org/10.1016/j.suscom.2021.100586.

[12] S. Patil, P. Z. Petkov, B. G. Bonev and H. Singh, "3-Axial EMC Field Probe Design Using Hexagonal Shaped Ultra Wide-Bandwidth Fractal Dipole Antenna for Frequency Range 0.5 to $12 \mathrm{GHz}$," 2018 IEEE International Conference on Environment and Electrical Engineering and 2018 IEEE Industrial and Commercial Power Systems Europe (EEEIC / I\&CPS Europe), 2018, pp. 1-5,

doi: 10.1109/EEEIC.2018.8494590.

[13] Y. A. Fadhel and H. N. Alsofi, "A Planar Self-Complementary Fractal Triangular Antenna for UWB Applications," 2019 International Conference on Advanced Science and Engineering (ICOASE), 2019, pp. 176-180, doi: 10.1109/ICOASE.2019.8723848.

[14] S. Das, S. Bhattacharjee and S. R. Bhadra Chaudhuri, "Fractal Loaded Hexagonal Wide Slot Antenna for Super Wide Band Application," 2018 IEEE Indian Conference on Antennas and Propogation (InCAP), 2018, pp. 1-4, doi: 10.1109/INCAP.2018.8770880.

[15] N. T. Atanasov, G. L. Atanasova, A. K. Stefanov and I. I. Nedialkov, "A Wearable, Low-Profile, Fractal Monopole Antenna Integrated with a Reflector for Enhancing Antenna Performance and SAR Reduction," 2019 IEEE MTT-S International Microwave Workshop Series on Advanced Materials and Processes for RF and THz Applications (IMWSAMP), 2019, pp. 67-69, doi: 10.1109/IMWS-AMP.2019.8880142.

[16] J. B. Benavides, R. A. Lituma, P. A. Chasi and L. F. Guerrero, "A Novel Modified Hexagonal Shaped Fractal Antenna with Multi Band Notch Characteristics for UWB Applications," 2018 IEEE-APS Topical Conference on Antennas and Propagation in Wireless Communications (APWC), 2018, pp. 830-833, doi:

10.1109/APWC.2018.8503774.

[17] S. Zhu and R. Langley, "Dual-Band Wearable Textile Antenna on an EBG Substrate," in IEEE Transactions on Antennas and Propagation, vol. 57, no. 4, pp. 926-935, April 2009. 
[18] S. Velan et al., "Dual-band EBG integrated monopole antenna deploying fractal geometry for wearable applications,” IEEE Antennas Wireless Propag. Lett., vol. 14, pp. 249-252, 2015.

[19] X. Zhu, Y. Guo and W. Wu, "A Compact Dual-Band Antenna for Wireless Body-Area Network Applications," in IEEE Antennas and Wireless Propagation Letters, vol. 15, pp. 98-101, 2016.

[20] S. Agneessens and H. Rogier, "Compact Half Diamond Dual-Band Textile HMSIW On-Body Antenna," in IEEE Transactions on Antennas and Propagation, vol. 62, no. 5, pp. 2374-2381, May 2014.

[22] S. Agneessens, S. Lemey, T. Vervust and H. Rogier, "Wearable, Small, and Robust: The Circular Quarter-Mode Textile Antenna," in IEEE Antennas and Wireless Propagation Letters, vol. 14, pp. 1482-1485, 2015.

[23] Susilo Ady Saputro, Jae-Young Chung, Hilbert curve fractal antenna for dual on- and off-body communication, Prog. Electro Magnet. Res. Lett. 58 (2016) 81-88.

[24] Manisha Gupta, and Vinita Mathur, "Wheel shaped modified fractal antenna realization for wireless communications," AEU- International Journal of Electronics and Communications, vol. 79, pp. 257-266, 2017.

[25] Sawant KK, Kumar CRS. CPW fed hexagonal micro strip fractal antenna for UWB wireless communications. Int $\mathbf{J}$ Electron Commun (AEÜ) (2014), http://dx.doi.org/10.1016/j.aeue.2014.07.022 